\section{ECONOMICS}

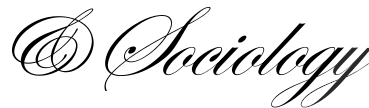

\title{
THE CONCEPT OF FTS ANYLYSIS IN FORECASTING TRENDS OF EXCHANGE RATE CHANGES
}

\begin{abstract}
The crisis in financial markets has contributed to a significant downturn in the global economy. Significant perturbations and high volatility have also been observed in the forex market. The purpose of this article is to determine which variables from the financial and commodity market affect the exchange rate changes. The article presents the concept of FTS analysis (Fundamental - Technical - Speculative) used to predict the direction of exchange rate changes. The author's FTS concept is a combination of two most popular forecasting methods and an attempt to add (parameterize) information on financial institutions' interventions in the forex market and generally understood speculations. The paper specifies explanatory variables and determines the nature of the occurring interdependencies. The FTS analysis allows for developing a computer system for decision support in the management of foreign exchange risk. At the same time, the paper draws attention to the complexity of the issue and shows possible directions for further research.
\end{abstract}

DOI: $10.14254 / 2071-$

789X.2014/7-2/14

JEL Classification: B4, C5, F4, G1

Keywords: forecasting, econometric model, FTS analysis, exchange rate.

\section{Introduction}

Increasing international economic cooperation and progressive liberalization of turnover in export and import requires the ability to solve a number of specific problems relating to the risk of exchange rate fluctuations. Changes in exchange rates may cause a decrease in revenues and an increase in costs. Additionally, with large commercial transactions and a significant scale of exchange rate fluctuations, foreign exchange losses arise, absorbing the expected profit and leading to losses, which may in turn threaten the existence of a company.

Opening of the national economy made numerous entities choose between the domestic and foreign supply and sales markets. The moment a given entity decides to enter the international arena in search for new sources of supply and sales, traditional knowledge of finance ceases to be sufficient, and it becomes imperative to understand the negative impact of the exchange rate fluctuations on future receivables and payables, which consequently may lead to huge losses, and, in extreme cases, even to bankruptcy (Begg, Fischer \& Dornbusch, 2007, p. 554). 
Undoubtedly, using methods of hedging against currency risk generates costs, and in the case of selecting wrong hedging instruments, they may also lead to financial losses. Therefore, if a company does not only think about comprehensively securing its international transactions, but also about benefitting from changes in the forex market and thus achieving additional profits (achieving profits without incurring additional costs, as in the case of hedging instruments, e.g. the most popular currency options), the most effective method is forecasting changes in the forex market (Diebold, Hahn \& Tay, 2006). Therefore, it should be ensured that the forecasts of changes in the forex market be as accurate as possible. However, due to the complexity of the issue and the likely inability to accurately predict the value of the exchange rate, it seems reasonable to simplify the simulation model so that it determines only the direction of change. Namely, to determine whether the trend is going to be positive or negative in relation to another currency. This information will be completely sufficient for the institutions operating in the international markets to make appropriate economic decisions.

\section{Assumptions for the FTS analysis}

Forecasting has always constituted a challenge for analysts. The only thing that is certain is that prices in financial markets will remain volatile. Predicting the future is difficult, especially when it comes to exchange rates (McNeil, Frey \& Embrechts, 2005). Their exact level in a few days or weeks cannot be forecast, despite an extensive econometric apparatus.

Analytical model is a hypothesis or a system of hypotheses which are formulated in a mathematical way (in the form of an equation or a system of equations, respectively), and show fundamental relations between real phenomena analysed (Witkowska, 2005). Mathematical model describes a given system using variables, which belong to different sets: real numbers, integers, logical values, character strings, etc. Variables represent certain characteristics of the system, for example, measured values of system outputs, or occurrence of events. The proper FTS analysis is a group of functions binding different variables, and thus describing the relations between the quantities in the system.

Some of the dependencies are going to be described with an econometric model, namely a formal mathematical notation of the existing economic regularities. What is required to build such a model is not only a good knowledge of economic theory, and mathematics and economics, but also economic practice. An econometric model should not only have a cognitive value from the economic point of view, but also a practical value, serving as a tool of inference about the future. In the models, in addition to functional dependencies defining the area of permissible decisions, there is the criterion function, also called the objective function, which allows for choosing the optimal variant out of those permissible. The FTS analysis should allow for describing the regularities existing in the economy which concern the exchange rate changes through mathematical models, and, additionally, through dependencies of behavioural economics.

Specification of the model consists in defining the explanatory variables, determining the present interdependencies, and developing the analytical form of the model equations. The process of model specification is usually about normative decision-making on its properties, performance and range, with some of those decisions being the result of the use of certain formal procedures. Specification of the model is based both on "a priori" information and statistical information. The "a priori" information is as follows:

- existing economic theories,

- generally known economic dependencies of settlement or balancing type,

- information from previously conducted econometric studies.

The dependencies of econometric forecasting are manifested by the fact that the basis of inference about the future is the observation of economic variables in the past. Regularities 
and relations between variables detected during statistical data analysis in the past are in turn the basis to build the model. Some models show how certain economic quantities depend on other quantities, and reflect the relation of a cause-effect nature between variables. The quantitative relations presented in the model can be applied for the future only if we accept the assumptions confirmed by reality as regards the conditions prevailing during the forecasting period. In economics the market is a place for purchase and sales transactions of goods, services and production factors (Anderloni, Llewellyn \& Schmidt, 2006). It is also a set of mechanisms governing these transactions and behaviours of both buyers and sellers (Hozer, 2007). In the science of economics, the market mechanism is the mutual interaction of various market components (Błach, 2009).

In the case of international market, the currency risk is a serious problem in the process of financial management (Bodnar \& Gebhardt, 2010). However, there is no doubt that it is worth trying to describe the behaviour of exchange rates, e.g. through mean reverting models, because with exchange rate models that work well on a given market, we can effectively identify exchange rate structures. By using "hedging" techniques, on the other hand, it is possible to reduce the risk associated with exchange rates (Adamska, 2004), or to use changes in the forex market which are favourable for a given company.

Although it is difficult to forecast exchange rates, the desire to conduct research and prognostic studies among professionals, and the need for information on the trends of changes in exchange rates is still increasing. The increased demand for currency forecasts is observed not only from the leading foreign trade companies, but also from private investors or commercial banks (Borowiecki, 2010). For the forecast results of the future exchange rates to be reliable, the forecasting entity should meet a number of requirements; otherwise their work may prove useless. These requirements include (Wisniewski, 2009):

- creating their own forecasting model,

- being able to obtain relevant information before other entities,

- being able to monitor even a relatively small short-term deviations from equilibrium on different forex markets,

- being able to quickly identify the direction and nature of government interventions in the forex market.

\section{FTS analysis in forecasting the direction of exchange rate changes}

The FTS analysis (Fundamental - Technical - Speculative) is a combination of two most popular forecasting methods used for securities (Lech, 2003), but at the same time it works perfectly well for currency forecasting, and an attempt to add (parameterize) information on financial institutions' interventions in the forex market and generally understood speculations. Forecasts calculated on the basis of fundamental analysis (selected macroeconomic factors) should work in the long-term perspective (Machała, 2009), and the forecast itself should set the values to which the market will aim at in the sense of achieving the state of equilibrium. The specified value takes into account selected macroeconomic factors of countries whose currencies are being compared. The method allows for comparing the so-called currency pairs, for example USD to EUR, and based on this principle it will determine the trend of one currency in relation to another. Having a higher number of comparisons, it is also possible to determine a general trend for a given currency. For the abovementioned example (for currencies of the highest international importance), it is sufficient to calculate this particular trend.

In theory and practice, the most common methods used for exchange rate forecasts are the fundamental analysis and the technical analysis. Although each of the methods has its drawbacks, they both have a large cognitive value for understanding the forces which affect 
the fluctuation of exchange rates both in a short-term and in a long-term perspective. The most common method of creating long-term exchange rate forecasts is fundamental analysis. The essence of this approach is based on a thorough analysis of macroeconomic, political and psychological factors that are likely to affect the change of exchange rates in the future. Fundamental analysis takes into account the effects of changes in the factors mentioned above and attributes significance to these factors, based on historical data (Ritchie, 1997).

The simplest approach to forecasting exchange rates in fundamental analysis is based on the use of the theory of purchasing power parity (PPP), which holds that the exchange rates (with a floating exchange rate) are determined primarily by differences in inflation rates. According to this theory, the currency of a country characterized by a high rate of inflation will depreciate against the currency of a country with a low rate of inflation. Thus, the exchange rate in the country with higher inflation should be reduced in relation to the currency of the country with lower inflation. The starting point for determining the forecast of an exchange rate is to determine the difference in the expected rate of inflation between countries whose currencies are subjected to the forecast.

"The Economist" calculates the index called the "Big Mac PPP", i.e. the exchange rate, which would equalize the price of Big Macs at McDonald's restaurants around the world, according to the following formula:

$$
s=\frac{\Pi_{h}}{\Pi_{f}}
$$

where:

$\mathrm{s}$ - exchange rate,

$\Pi_{h}$ - price in domestic currency,

$\Pi_{f}-$ price in foreign currency.

However, the condition for PPP to work is the freedom of trade and the omission of transportation costs, which is not consistent with reality. In contrast, the relative purchasing power parity theory says that the change in exchange rates corresponds to changes in price levels, i.e., inflation rates, both domestically and abroad (Batten, Mellor \& Wan, 1993).

where:

$$
\frac{s_{t}}{s_{0}}=1+e=\frac{1+p_{h}}{1+p_{f}}
$$

$s_{0}$ - value of a foreign currency unit expressed in the domestic currency at the beginning of a given period of time,

$s_{\mathrm{t}}$ - value of a foreign currency unit expressed in the domestic currency at the end of a given period of time,

$\mathrm{e}$ - rate of change in the exchange rate i.e. the rate of depreciation or appreciation,

$\mathrm{p}_{\mathrm{h}}$ - domestic inflation rate,

$\mathrm{p}_{\mathrm{f}}-$ foreign inflation rate,

$1+\mathrm{p}_{\mathrm{h}}-$ new level of domestic prices,

$1+p_{f}-$ new level of foreign prices.

Another theory is the interest rate arbitrage. It explains the change in exchange rates in a short-term perspective, and involves comparing interest rates, which are a measure of the capital cost, in various countries. International Fisher Effect, analogously to the theory of purchasing power parity, combines exchange rate changes with changes in interest rates. According to the relative theory of purchasing power parity, the differences in inflation rates should be reflected in the changes in the exchange rate, and according to the Fisher effect, the 
differences between nominal interest rates will be reflected in the changes in the exchange rate (Najlepszy, 1993).

$$
\frac{s_{t}-s_{0}}{s_{0}}=\frac{i_{h}-i_{f}}{1+i_{f}},
$$

where:

$s_{0}$ - value of a foreign currency unit expressed in the domestic currency at the beginning of a given period of time,

$s_{t}$ - value of a foreign currency unit expressed in the domestic currency at the end of a given period of time,

$\mathrm{i}_{\mathrm{h}}$ - domestic inflation,

$\mathrm{i}_{\mathrm{f}}-$ foreign inflation.

Thus, in accordance with the International Fisher Effect, the rate of change in exchange rates depends on the difference between the domestic and foreign nominal interest rate. In contrast, the interest rate parity law states that there is a relation between the differences in nominal interest rates and the difference between the spot rate and the forward rate (Gubler, 2011).

The opposite of fundamental analysis is technical analysis, whose proponents produce short-term forecasts based on historical exchange rates and the volume of currency flows in the market. In technical analysis, economic, political and psychological factors are completely ignored when creating forecasts. Here, forecasting success is mainly about the possibility to discover a new interaction system between currency flows and exchange rate relationships, which confirms the statistical repeatability of these interactions in a given period of time and allows for making accurate predictions. Technical analysis is based on three fundamental assumptions:

- currency prices are subject to trends. Market prices move in certain directions and are subject to trends. Identification and tracking of price trends allows for finding the signals that they are going to end (graph analysis);

- market is a mechanism that discounts everything. Price reflects the conditions which shape the expectations of market participants and affect the relation between supply and demand;

- processes in the market reoccur. Certain behavioural patterns tend to repeat themselves. These historical systems may constitute a clue for the forecasting purposes.

In technical analysis, graphical presentation of exchange rates, and the rate of change and moving average models are used to produce forecasts. Supporters of graph analysis think that the shape of exchange rates in the past allows for identification of certain patterns called technical formations, i.e. formations which predict change or continuation of the current trend. The trend is determined by connecting (with a straight line) the so-called turning points on an exchange rate graph - in an upward trend, the "lows" are connected, in a downward trend - the "peaks". Detecting a proper formation allows for determining the direction of a trend change in the near future. Additionally, graph analysis proponents analyse long-term rate trends, and use them as a basis for short-term forecasting (Manikowski and Tarapaty, 2002). Technical analysis uses:

- the rate of change model which analyses the rate of change in prices. The increase in the rate of change indicates the continuation of a trend, and the decline in the rate - a radical change in a trend; 
- the moving average model, in which the price trends are forecast by analysing the short- and long-term moving averages of prices. A change in the trend is expected when the long-term moving average crosses the short-term one.

Unfortunately, separate forecasts produced using fundamental analysis or technical analysis have one thing in common - they rarely work. The results of studies devoted to the accuracy of forecasts indicate that these forecasts are more often wrong than correct. This confirms the thesis about the unpredictability of future foreign currency exchange rates and the need to seek new methods of forecasting, or to improve the existing ones.

In the light of the theory of exchange rates in a market economy, all the research efforts that seek to objectively determine future changes in currency values do not give the desired results. Those who make a living forecasting exchange rates quickly discover that the reality is more complex than it seems to be when based of theories. Professionals who deal with forecasting can at best hope that they will be able to predict the direction of change and the exchange rate value in half of the cases. Therefore, the FTS analysis will not forecast the future value of exchange rates, but the trend itself, positive - an increase, or negative - a decrease in the exchange rate of one currency in relation to another.

In most cases, professional FX forecasts are based on complex statistical models, and the attention of the entity producing the forecast focuses on the evaluation of how the interaction of various factors affects changes in demand and supply of the analysed currency. The future value of a currency is determined by estimating the exchange rate at which the volume of supply and demand will be levelled. A comparison of exchange rate forecast using statistical models with real exchange rates in the currency market shows that these models are often inaccurate. The unreliability of statistical models may stem from the fact that the historical significance of the factors affecting the exchange rate may lead to erroneous indications regarding the correlation between these factors in the future, or that factors (variables) that were not included in the forecasting model affected the forecast. Also, psychological factors, whose inclusion in mathematical models is a significant challenge, are also important.

In econometrics, there are four groups of explanatory variables (so-called predictors) distinguished with respect to the form of correlation between a given explanatory variable and a dependent variable (Dziechciarz et al., 2003):

- stimulant (larger-the-better) - a positive correlation with a dependent variable, an increase in the explanatory variable leads to an increase in the dependent variable,

- destimulant (smaller-the-better) - a negative correlation with a dependent variable, an increase in the explanatory variable leads to a decrease in the dependent variable,

- nominant (nominal-the-best) - the variable resembles a stimulant to a certain point, called the nominal value, and then it resembles a destimulant,

- neutral - variable independent of the dependent variable, or of too weak a dependency to be used in the model.

Strength of the currency is a derivative of the condition of the economy. If a country has a strong and efficient economy, then its currency is also strong. Exchange rate is strongly related to both the economy and economics. An overview of the macroeconomic situation of a country allows for determining the nominal value of the exchange rate, which may be regarded as the value of equilibrium, if other factors in addition to those taken into account in the fundamental analysis have not affected the exchange rate. 
Table 1. Selected factors of the fundamental analysis and their influence on the exchange rate forecast

\begin{tabular}{|c|c|c|c|c|}
\hline $\begin{array}{c}\text { Factors of the } \\
\text { fundamental analysis }\end{array}$ & Change & $\begin{array}{l}\text { Exchange } \\
\text { rate }\end{array}$ & Dependency & Classification \\
\hline $\begin{array}{l}\text { Gross Domestic Product } \\
\text { (GDP) }\end{array}$ & $\begin{array}{l}\text { Positive } \\
\text { (increase) }\end{array}$ & $\begin{array}{l}\text { Exchange rate } \\
\text { increase }\end{array}$ & Stimulant & Quantitative \\
\hline Level of interest rates & $\begin{array}{l}\text { Positive } \\
\text { (increase) }\end{array}$ & $\begin{array}{l}\text { Exchange rate } \\
\text { increase }\end{array}$ & Stimulant & Quantitative \\
\hline Unemployment & $\begin{array}{c}\text { Positive } \\
\text { (increase) }\end{array}$ & $\begin{array}{c}\text { Exchange rate } \\
\text { decrease }\end{array}$ & Destimulant & Quantitative \\
\hline Inflation & $\begin{array}{c}\text { Positive } \\
\text { (increase) }\end{array}$ & $\begin{array}{c}\text { Exchange rate } \\
\text { decrease }\end{array}$ & Destimulant & Quantitative \\
\hline Balance of payments & $\begin{array}{l}\text { Positive } \\
\text { (increase) }\end{array}$ & $\begin{array}{l}\text { Exchange rate } \\
\text { increase }\end{array}$ & Stimulant & Quantitative \\
\hline Political stability & $\begin{array}{l}\text { Positive } \\
\text { (increase) }\end{array}$ & $\begin{array}{c}\text { Exchange rate } \\
\text { increase }\end{array}$ & Nominant & Qualitative \\
\hline Budget deficit & $\begin{array}{l}\text { Positive } \\
\text { (increase) }\end{array}$ & $\begin{array}{c}\text { Exchange rate } \\
\text { decrease }\end{array}$ & Nominant & Quantitative \\
\hline Public debt ( $>50 \%$ GDP) & $\begin{array}{l}\text { Positive } \\
\text { (increase) }\end{array}$ & $\begin{array}{c}\text { Exchange rate } \\
\text { decrease }\end{array}$ & $\begin{array}{c}\text { Nominal } \\
\text { (destimulant) }\end{array}$ & Quantitative \\
\hline
\end{tabular}

Source: Own work based on: Zając, J. (2002), Polish currency market in practice, K.E.LIBER Publishing House, Warsaw, pp. 251-260.

Most factors of the fundamental analysis for currencies are quantitative, so they can be written down and calculated using appropriate mathematical formulas, as with the GDP variable. GDP - expenditure approach (a) and income approach (b):

a) GDP = consumption + investment + government spending + export - import + change in inventories;

b) GDP = earned income + capital income+ state income + depreciation;

Some factors taken into account in the analysis are characterized by specific values, for example interest rates, which are compared between countries whose currencies are analysed. In contrast, qualitative factors can be parameterized using the ranking method, and in accordance with the accepted principle, specific values can be assigned to the assessed actual state. Still, creating a comprehensive decision support system that would provide the final answer is complicated. Therefore, certain partial stages, which are going to forecast the direction of change of the so-called currency pairs, should be automated through appropriate calculation models. And because of the complexity of the issue, final analyses will be conducted by an experienced specialist (human), as the currency market is undoubtedly associated with social (psychological) processes. One of significant factors shaping the exchange rate is information regarding the policy pursued by the government of a particular country. The situational and sectorial analyses provide information on the conditions in which a country operates and is going to operate, strategy it adopted, and direction of its development. The financial analysis of a country, on the other hand, answers the question about the current value of country's activities. Certainly, these factors, impossible to parameterize quantitatively, also affect the current valuation of an exchange rate.

In contrast, the technical analysis sets short-term trends. Therefore, a standard analysis of graphs presenting changes in an exchange rate, as is the case with the value of shares, will forecast the change in the direction of the exchange rate - a positive change (the exchange rate increase), or a negative change (the exchange rate decrease). 
The following sample graphs of changes in exchange rates, pairs EUR / PLN and USD / PLN of one month, will be presented the concept of the author's analysis of the FTS.

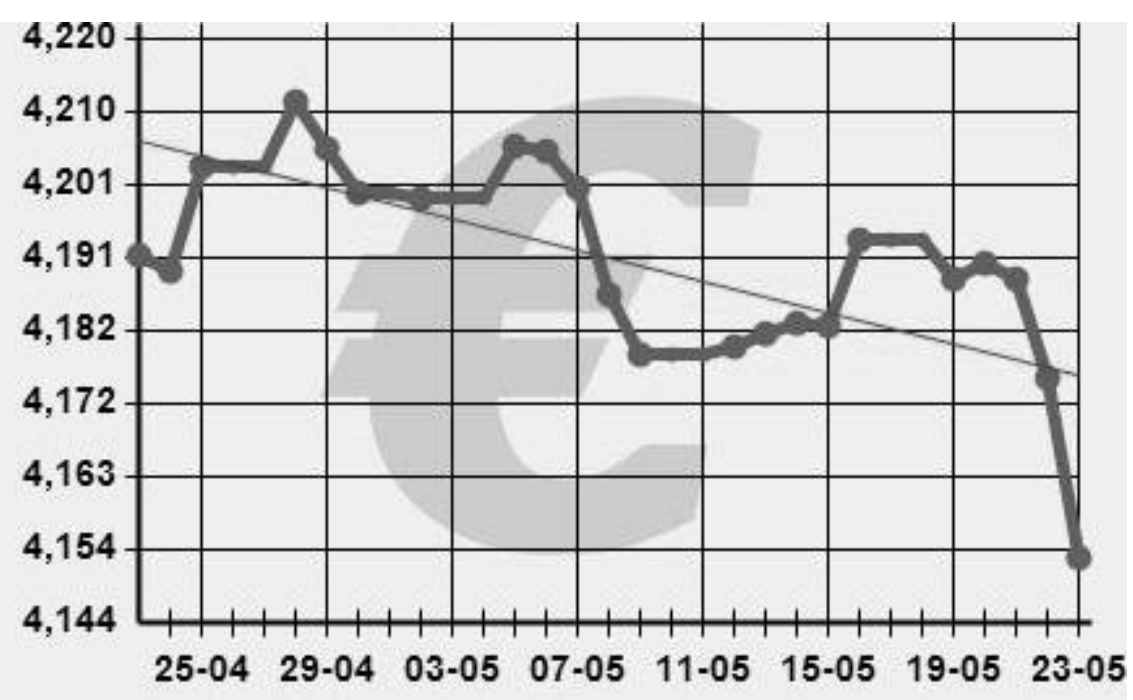

Figure 1. Quotations exchange rate for EUR / PLN in the period 23.04 - 23.05 in 2014 Source: Polish National Bank, http://www.nbp.pl/ (access: 24/05/2014).

As mentioned earlier analysis consists of three components, or another of the three stages. The first of them on the basis of fundamental analysis determines the starting point of the trend in the long run, the graphs below the solid line. For EUR / PLN trend at this time is decreasing for the euro exchange rate. And for the pair USD / PLN, this trend is growing. The second step is to determine the short-term recommendations based on technical analysis involving the analysis of the charts by the knowledge of the accuracy of the statistical fluctuations in the currency market. The third and last stage is called. speculative analysis, which examines the information about the interventions of state and financial institutions in the foreign exchange market and broad events (eg. political, military, etc.) that may have an impact on changes in exchange rates. For EUR / PLN such event occurred 20/05/14, and for USD / PLN 05/06/14.

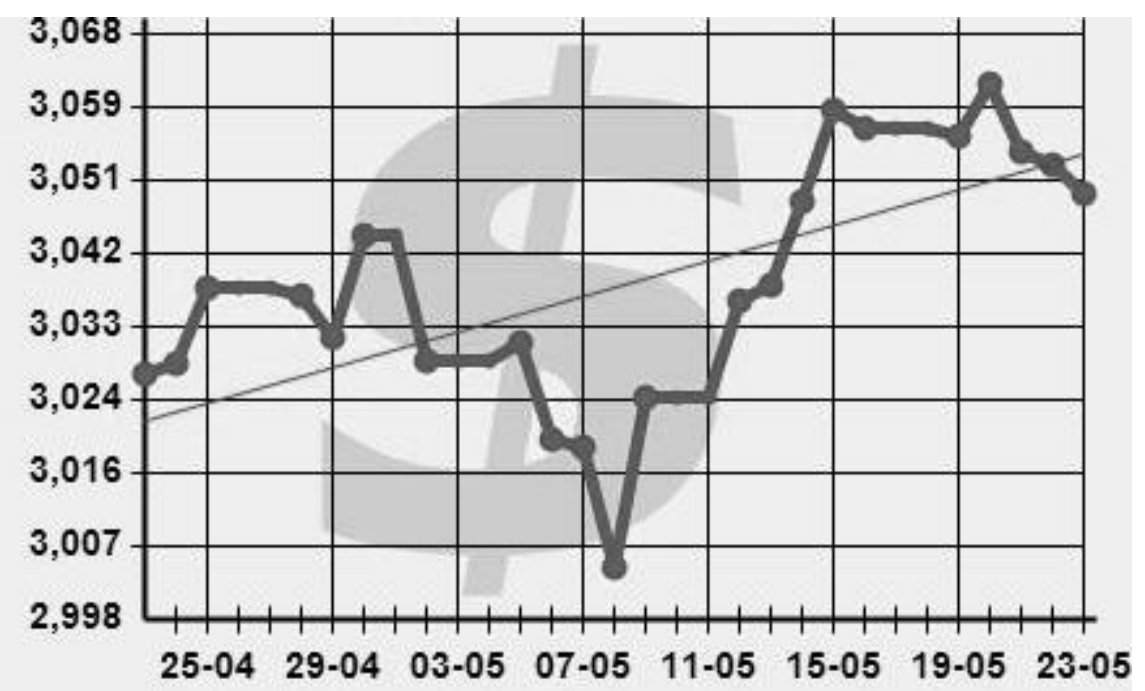

Figure 2. Quotations exchange rate for USD / PLN in the period 23.04-23.05 in 2014 Source: Polish National Bank, http://www.nbp.pl/ (access: 24/05/2014). 
Binary coding is used so that it is possible both to analyse the comprehensive approach used in the FTS analysis and to implement it in the decision support computer system (direction of change indicated by the system). If the speculative analysis results in the information about the speculative interventions of state and financial institutions in the foreign exchange market, it will be encoded it in the system as 1 for such activities and 0 for the absence of such activities. Generally understood speculative activities will be taken into account if they relate to entities that have the ability to reverse the trend through their actions. Activities aiming at an increase in the rate of a base currency will be encoded it as 1, whereas a decrease will be encoded as -1 . Such information will allow for forecasting the so-called speculative shocks, which reverse the trend, can be contrary to the equilibrium value calculated in the FT analysis and last even for a long period, as shown by the events of recent years.

Table 2. Recommendations in the FTS analysis

\begin{tabular}{ccccc}
\hline No. & $\mathbf{F}$ & $\mathbf{T}$ & $\mathbf{S}$ & Recommendation \\
\hline $\mathbf{1}$ & + & + & 0 & ++ \\
\hline $\mathbf{2}$ & - & - & 0 & -- \\
\hline $\mathbf{3}$ & + & - & 0 & - or $+/-$ \\
\hline $\mathbf{4}$ & - & + & 0 & + or $+/-$ \\
\hline $\mathbf{5}$ & + & + & 1,1 & +++ \\
\hline $\mathbf{6}$ & - & + & 1,1 & ++ \\
\hline $\mathbf{7}$ & - & - & 1,1 & $+/-$ \\
\hline $\mathbf{8}$ & + & - & 1,1 & + \\
\hline $\mathbf{9}$ & - & - & $1,-1$ & --- \\
\hline $\mathbf{1 0}$ & + & - & $1,-1$ & -- \\
\hline $\mathbf{1 1}$ & - & + & $1,-1$ & - \\
\hline $\mathbf{1 2}$ & + & + & $1,-1$ & $-/+$ \\
\hline
\end{tabular}

Explanation: number of pluses (+) or minuses (-) on a scale of one to three is the rate and/or size of the change; + I - stands for minor changes within a short time.

Source: own work.

The FTS analysis will allow for a partial automation of forecasting exchange rate changes for a selected currency pair, or a general trend for the analysed currency. Parameterization in the decision support system of selected macroeconomic values (fundamental analysis), factors inferred from trends (technical analysis) and intervention information will simplify and shorten the analysis of the possible changes in the forex markets. This assistance will improve the speed and accuracy of decisions made by currency market analysts, which will allow for the possibility of a more effective participation in profits resulting from the exchange rate changes. The following table shows some simulations analysis of the FTS for the actual data.

Table 3. Examples of FTS analysis on the example of the actual data pair EUR / PLN

\begin{tabular}{cccccccc}
\hline No. & $\begin{array}{c}\text { Course in day } \\
\text { recommendation }\end{array}$ & $\mathbf{F}$ & $\mathbf{T}$ & $\mathbf{S}$ & Recommendation & $\begin{array}{c}\text { Course in the } \\
\text { next quotation }\end{array}$ & Direction \\
\hline $\mathbf{1}$ & $4.1472(31.12 .13)$ & + & + & 0 & ++ & $4.1632(02.01 .14)$ & growth \\
\hline $\mathbf{2}$ & $4.1776(09.01 .14)$ & + & - & 0 & - lub $+/-$ & $4.1745(10.01 .14)$ & decrease \\
\hline $\mathbf{3}$ & $4.1679(23.01 .14)$ & + & + & 1,1 & +++ & $4.2017(24.01 .14)$ & growth \\
\hline $\mathbf{4}$ & $4.2014(24.01 .14)$ & - & - & 0 & -- & $4.2291(27.01 .14)$ & $\begin{array}{c}\text { growth } \\
\text { (mistake) }\end{array}$ \\
\hline $\mathbf{5}$ & $4.1780(20.02 .14)$ & + & + & $1,-1$ & $-/+$ & $4.1680(21.02 .14)$ & decrease \\
\hline
\end{tabular}




\begin{tabular}{cccccccc}
\hline $\mathbf{6}$ & $4.1991(10.03 .14)$ & + & - & 0 & - lub $+/-$ & $4.2171(11.03 .14)$ & growth \\
\hline $\mathbf{7}$ & $4.1840(15.04 .14)$ & + & + & 0 & ++ & $4.1925(16.04 .14)$ & growth \\
\hline $\mathbf{8}$ & $4.1925(16.04 .14)$ & - & + & $1,-1$ & - & $4.1968(17.04 .14)$ & $\begin{array}{c}\text { growth } \\
\text { (mistake) }\end{array}$ \\
\hline $\mathbf{9}$ & $4.1968(17.04 .14)$ & - & + & $1,-1$ & - & $4.1820(18.04 .14)$ & decrease \\
\hline $\mathbf{1 0}$ & $4.1524(23.05 .14)$ & + & + & 0 & ++ & $?(26.05 .14)$ & $?$ \\
\hline
\end{tabular}

Source: own work.

An example of the application analyzes the concept of FTS indicates to the correct classification of the factors that affect the change in the exchange rate, but also show great difficulty in correctly predicting the direction of changes in exchange rates, particularly due to the behavioral nature of the currency market.

\section{Conclusions and implications}

Due to changes that occur in the way financial markets operate, behaviour of individual instruments is analysed using not only information directly relating to a given value, but also relating to its environment. Exchange rates belong to the group of instruments that are highly responsive to environmental changes. Different factors, both economic and non-economic, cause changes in exchange rates. Identification of these factors and the analysis of their influence on exchange rates will often allow for using the acquired knowledge in the process of forecasting exchange rate changes. More and more national (regional) economies are becoming increasingly more open to international trade. The ongoing globalisation makes the turmoil in financial markets translate into the condition of markets all over the world. Globalization also reduces the possibility of supervision over the activities of financial institutions, increasing investment risk at the same time. Additionally, we are witnessing a specific feedback between financial markets. Therefore, building a model most accurately reflecting changes in the currency market is such a difficult and complicated task. This paper determines the variables from the financial and commodity markets that affect the exchange rate changes. The next step will be to study the quantitative relationship between events and economic variables affecting the currency market. It should be noted that the analysis of historical data clearly indicates the occurrence of a relation between the future value of the exchange rate and current levels of variables from the financial markets. The concept of the FTS analysis is a combination of two most popular forecasting methods and an attempt to add (parameterize) information on financial institutions' interventions in the forex market and generally understood speculations. The FTS analysis allows for developing a computer system for decision support in the management of foreign exchange risk.

\section{References}

Adamska, A. (2004), The role and responsibilities of the CFO, Ed. OE, Cracow.

Anderloni, L., Llewellyn, D.T., Schmidt, R.H. (2006), Financial Innovation in Retail and Corporate Banking, Edward Elgar, Cheltenham.

Batten, J., Mellor, R. and Wan, V. (1993), Foreign Exchange Risk Management Practices and Products used by Australian Firms, Journal of International Business Studies, Vol. 24, No. 3 (3rd Qtr.), Palgrave Macmillan Journals, pp. 557-573.

Begg, D., Fischer, S., Dornbusch, R. (2007), Macroeconomics, Polish Economic Publishing House, p. 554. 
Błach, J. (2008), Financial Innovations and Their Role in the Modern Financial System Identification and Systematization of the Problem, Financial Internet Quarterly ,eFinance", Vol. 7, No. 3.

Bodnar, G.M., Gebhardt, G. (2010), Derivatives usage in risk management by German non financial firms, Journal of International Financial Management \& Accounting, Vol. 10, Issue 3, pp. 153-187.

Borowiecki, R. (2010), Enterprise in the Face of Challenges of the Modern Economy, Cracow University of Economics, Cracow.

Crawford, G., Sen, B. (1998), Derivatives - financial decision-making tool, Liber Publishing House, Warsaw.

Diebold, F., Hahn, J., Tay, A. (2006), Multivariate Density Forecast Evaluation and Calibration In Financial Risk Management: High-Frequency Returns on Foreign Exchange, The Review Economics and Statistics, Vol. 81, No. 4, pp. 661-673.

Dziechciarz, J. (edit.) (2003), Econometrics. Methods, Examples, Exercises, Wrocław University of Economics Publishing House.

Dufey, G., and Srinivasulu, S. (Winter, 1983), The Case for Corporate Management of Foreign Exchange Risk, Financial Management, Vol. 12, No. 4, New York: John Wiley \& Sons, pp. 54-62.

Gubler, Z.J. (2011), The Financial Innovation Process: Theory and Application, Delaware Journal of Corporate Law, Vol. 36.

Hozer, J. (2007), Applied Econometrics in Examples and Exercises, Szczecin University Publishing House, Szczecin.

Lech, A. (2003), Risk Management - Key to Stability, WIB Publishing House, Warsaw.

McNeil, A., Frey, R., Embrechts, P. (2005), Quantitative Risk Management: Concepts, Techniques, and Tools, Princeton series in finance, New Jersey.

Machała, R. (2009), Financial management and business valuation, Oficyna Publishing House, Warsaw.

Manikowski, A., Tarapaty, Z. (2002), Forecasting and Simulation, Warsaw School of Economics.

Najlepszy, E. (1993), International Corporate Finances, Bafina, Poznań.

Ritchie, J.C., (1997), Fundamental Analysis, WIG-PRESS Publishing House, Warsaw.

Wiśniewski, J. (2009), Microeconomics, Publishing House of Nicolaus Copernicus University in Toruń.

Witkowska, D. (2005), Basic Econometrics and Forecasting Theory, Economic Publishing House Cracow.

Zając, J. (2002), Polish currency market in practice, K.E.LIBER Publishing House, Warsaw, pp. 251-260.

Polish National Bank, http://www.nbp.pl/ - access 24 May 2014.

waluty.com.pl - access 12 September 2013.

http://www.eiu.com/public/ (Economist Intelligence Unit) - access 08 January 2014. 